\title{
NGHIÊN CỨU ÚNG DỤNG SỐ LIỆ MƯA VỆ TINH MÔ PHỎNG LŨ KHU VỰC TRUNG LƯU SÔNG MÃ
}

\author{
Nguyễn Tiến Kiên ${ }^{1}$
}

Tóm tắt: Hiện nay, các hệ thống dụ báo lũ trên thế giới đã tích hợp nhiều nguồn dũ liệu mura là sản phẩm ra đa, vệ tinh để bổ sung và kết hợp với mưa thực đo được phát triển phổ biếntai các co quan khí tượng thủy văn ở các nước tiên tiến như Mỹ, Nhật, Trung Quốc, Hàn Quốc...Báo cáo này sẽ trình bày kết quả tính toán dòng chảy lũ trên dòng chính sông Mã dựa trên nghiên cưu ứng dụng mô hình thủy văn IFAS của Viện nghiên cưu công chính Nhật PWRI. Nguồn dũ liệu đầu vào mô hình là mura thực đo và sản phẩm mura vệ tinh GSMaP_NRT. Kết quả tính toán cho thấy vói mạng luóoi trạm thua thớt, việc mô phỏng dòng chảy lũ cho các vị trí khu vục trung và thuợng lưu sông Mã là không tốt với cả hai nguồn số liệu mưa thực đo và mưa vệ tinh. Khi so sánh các kết quả tính toán, một số truoòng hợp việc sủ dụng mura vệ tinh cho kết quả khả quan hơn khi sử dụng mưa thưc đo, đây là tiền đề cân nhắc việc áp dụng số liệu mưa vệ tinh trong tính toán dòng chảy lũ cho nhũng vùng không có hoặc it trạm đo nhu khu vục trung và thượng luu sông Mã.

Từ khóa: GSMaP_NRT, Lưu vục sông Mã, Mô phỏng dòng chảy lũ, Mô hình IFAS.

Ban Biên tập nhận bài: 08/12/2019 Ngày phản biện xong: 12/1/2020 Ngày đăng bài: 25/01/2020

\section{1. Đặt vấn đề}

Thực trạng mạng lưới trạm thưa thớt đang là vấn đề khó khăn và thách thức trong việc tính toán mô phỏng dòng chảy và dự báo lũ trên lưu vực. Nhiều nghiên cứu của các nhà khoa học trên thế giới [1-2,5] tích hợp các nguồn số liệu mưa thực đo và vệ tinh vào mô hình thủy văn thủy lực tính toán dòng chảy cho các lưu vực sông không có hoặc thiếu trạm đo mặt đất và chứng minh đó là giải pháp tính hiệu quả tính toán mô phỏng dòng chảy trên lưu vực sông. Trên thực tế, một số cơ quan khí tượng thủy văn cũng đã tích hợp nhiều nguồn dữ liệu viễn thám như mưa vệ tinh, mưa dự báo số trị, dữ liệu cao độ số, thảm phủ...và số liệu thực đo vào trong các mô hình thủy văn, thủy lựctrong hệ thống dự báo lũ.

Sông Mã là sông lớn liên quốc gia với tổng diện tích toàn lưu vực là $28400 \mathrm{~km}^{2}$, trong đó phần diện tích lưu vực thuộc Việt Nam là $17600 \mathrm{~km}^{2}$ chiếm $62 \%$ tổng diện tích, tại Lào là 10800 km2 chiếm 38\% diện tích lưu vực.Hiện nay, thực trạng mạng lưới trạm khí tượng thủy văn trên lưu vực thưa thớt, đặc biệt khu vực

${ }^{1}$ Trung tâm Dự báo khi tượng thuỷ văn quốc gia Email:kien.wrs@gmail.com trung và thượng lưu vực. Trên lưu vực và vùng lân cận có 12 trạm khí hậu quan trắc các yếu tố như nhiệt độ, độ ẩm, bốc hơi, nắng, gió, mưa và các đặc trưng khí tượng khác. Ngoài ra còn có 51 trạm đo mưa được đặt ở các trạm thuỷ văn, bưu điện, thị trấn. Hầu hết các trạm có số liệu dài như Thanh Hoá từ 1899 - 1948, 1955- nay hoặc Hồi Xuân 1923 - 1944, 1960 - nay, Bái Thượng 1921 - 1946, 1955 - 1990 v.v... tới nay, trên lưu vực còn 6 trạm khí tượng, 42 trạm đo mưa. Vùng thượng nguồn sông Mã có 2 trạm khí tượng: Tuần Giáo, trạm Sông Mã. Còn các trạm Sơn La, Cò Nòi, Yên Châu, Mộc Châu nằm ở khu vực lân cận [4].

Trên lãnh thổ Lào không có tài liệu khí tượng hoặc đo mưa nào được thu thập. Phần lãnh thổ Thanh Hoá, Nghệ An có mạng lưới trạm khí tượng, đo mưa khá dày, chủ yếu là đo mưa. Bài báo này trình bày kết quả ứng dụng mô hình thủy văn IFAS tích hợp sản phẩm dữ liệu mưa vệ tinh GSMaP_NRT, số liệu mưa thực đo mô phỏng dòng chảy lũ trong thời gian từ năm 2000 - 2009 (thời gian hệ thống sông Mã chưa chịu quá nhiều tác động của hồ chứa trên lưu vực) nhằm đánh giá những nghiên cứu tính toán dự báo lũ dựa 
trên dữ liệu mưa vệ tinh về sau. Lưu vực sông Mã được lựa chọn để nghiên cứu vì đây là lưu vực có địa hình đa dạng, trải từ miền núi cao xuống đồng bằng. Với thực trạng mạng lưới đo đạc khí tượng thủy văn khi vùng hạ lưu có mạng lưới đo mưa khá dày, vùng thượng lưu ít trạm đo, thậm chí không có trạm đo tại khu vực đất nước Lào (chiếm 38\%) là những khó khăn trong việc tính toán dòng chảy trên hệ thống sông nói chung và dự báo lũ nói riêng.

Chính vì vậy, nghiên cứu xây dựng mô hình thủy văn có sử dụng nguồn mưa thực đo và mưa vệ tinh để mô phỏng dòng chảy lũ sẽ đánh giá hiệu quả ứng dụng mưa vệ tinh GSMAP cho lưu vực sông Mã sẽ có nhiều ý nghĩa thực tiễn phục vụ bài toán tính toán thủy văn và dự báo lũ về sau.

\section{Phương pháp nghiên cứu}

\subsection{Mô hình thủy văn IFAS}

IFAS (Integrated Flood Analysys System) được gọi là Hệ thống phân tích lũ tổng hợp do Viện nghiên cứu công chính Nhật Bản PWRI (Public Works Research Institute) [3,7]. IFAS cung cấp giao diện cho đầu vào không chỉ gồm dữ liệu mưa ở các trạm đo mặt đất mà còn dựa dữ liệu mưa vệ tinh, và các chức năng GIS để tạo mạng lưới kênh sông và ước tính các tham số của công cụ phân tích chế độ dòng chảy (mô hình thủy văn thông số phân bố PWRI) và giao diện để hiển thị kết quả đầu ra. Được phát triển từ năm 2007, qua các hoạt động nghiên cứu được triển khai bởi Trung tâm quốc tế về quản lý thảm họa và rủi ro về nước (ICHARM) dưới sự bảo trợ của UNESCO, hệ thống IFAS đã được chuyển giao, đào tạo miễn cho các nước đang phát triển ở Châu Á, trong đó có Việt Nam vào năm 2011.

Nghiên cứu ứng dụng IFAS trong tính toán thủy văn tại Việt Nam điển hình có thể kể đến là đề tài khoa học cấp Bộ năm 2013 "Nghiên cứu ứng dụng số liệu vệ tinh, mưa dự báo số trị kết hợp số liệu bề mặt trong dự báo lũ hệ thống sông Hồng - Thái Bình" của TS. Đặng Ngọc Tĩnh [6]. Dựa trên nghiên cứu này và sự hỗ trợ trong khuôn khổ nghiên cứu của "Chương trình Chu trình nước Châu Á”, TS. Đặng Ngọc Tĩnh đã nghiên cứu xây dựng hệ thống dự báo lũ cho lưu vực sông Thái Bình với sự tích hợp của mô hình thủy văn IFAS, mô hình thủy lực MIKE 11 với dữ liệu mưa đầu vào từ các trạm đo, mưa vệ tinh GSMaP_NRT, mưa dự báo từ các mô hình số trị ECMWF, GFS, HRM và hệ thống dự báo vẫn được sử dụng trong nghiệp vụ. Hiện nay, một số cơ quan dự báo khu vực như Bắc Trung Bộ, Việt Bắc đã ứng dụng mô hình IFAS để xây dựng những phương án dự báo lũ cho các hệ thống sông trong nhiệm vụ được giao.

Một số ưu điểm chính của IFAS đó là khả tích hợp nhiều nguồn dữ liệu mưa ước lượng từ ảnh mây vệ tinh, radar, số liệu thực đo làm đầu vào; phân tích, tính toán dòng chảy trên lưu vực sông dựa trên mô hình thủy văn thông số phân bố; tự thiết lập mô hình tính toán dòng chảy trên cơ sở số liệu từ hệ thống thông tin địa lý toàn cầu (GIS), dữ liệu viễn thám gồm địa hình, thảm phủ, loại đất...; có khả năng hiện thị trực quan kết quả ở dạng đồ thị, bảng biểu và biểu đồ.

Số liệu mưa vệ tinh và mưa thực đo bề mặt được nhập vào như số liệu dạng ô lưới (grid). Đường phân thủy được tạo ra từ số liệu mô hình số độ cao (DEM). Mô hình tính toán được tạo thành bằng thiết lập các thông số trên cơ sở số liệu sử dụng đất hoặc lớp phủ, điều kiện địa chất và chất đất [6].

Mô hình thủy văn trong IFAS (gọi tắt mô hình IFAS) thuộc mô hình có thông số phân bố bao gồm ba mô hình bộ phận là mô hình nước mặt, mô hình nước ngầm và mô hình nước trong sông với cấu trúc của hệ thống mô hình thủy văn bao gồm 3 mô hình bộ phận được tổng hợp ở bảng 1 và minh họa ở hình 1 . 


\section{Cấu trúc của IFAS}

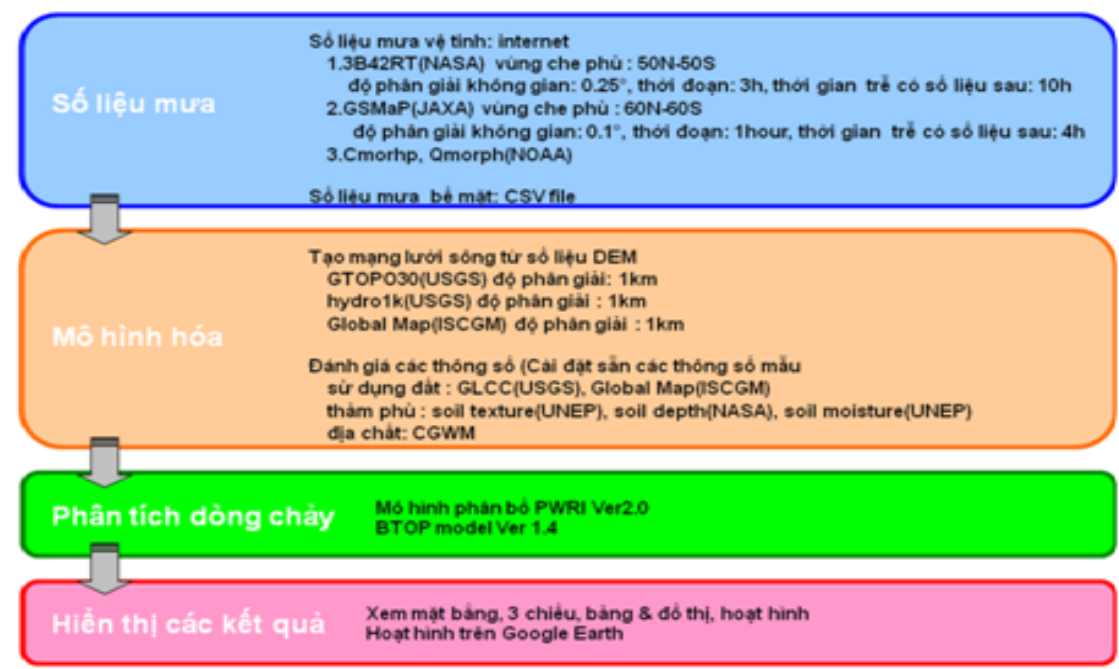

Hình 1. Câu trúc chính của IFAS

Bảng 1. Cấu trúc của hệ thống mô hình thủy văn

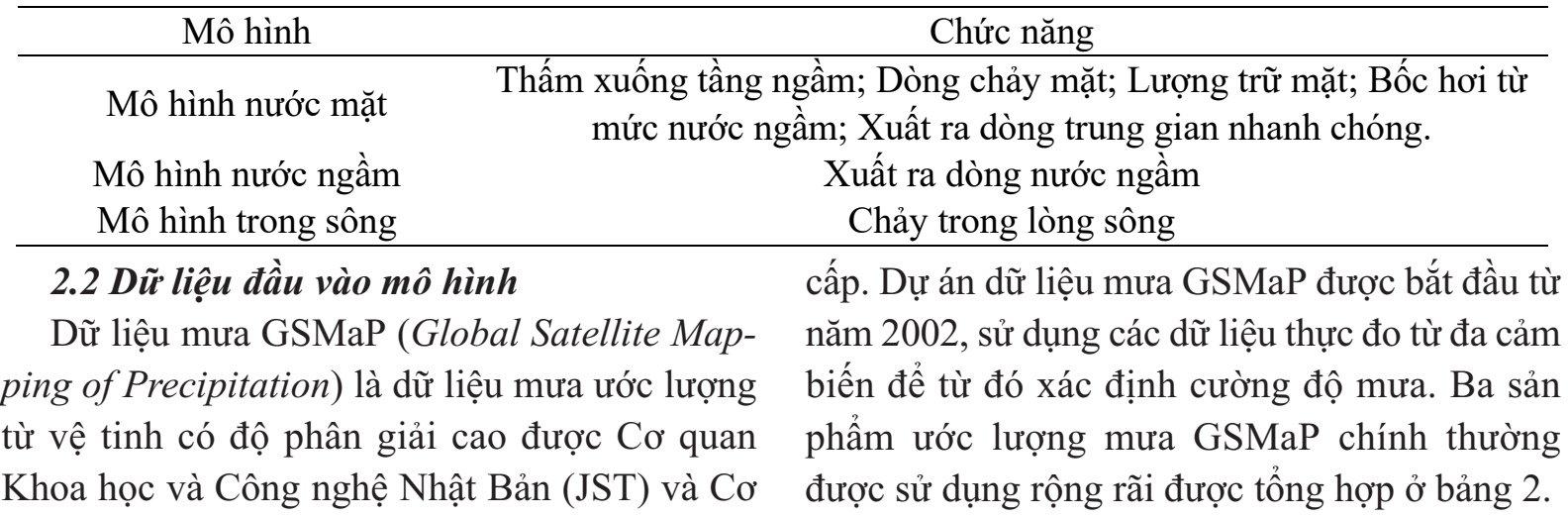
quan Khám phá Vũ trụ Nhật Bản (JAXA) cung

Bảng 2. Các sản phẩm ước lượng mưa GSMaP

\begin{tabular}{ccccc}
\hline Loại sản phẩm & Tên & Độ phân giải & Độ trễ & Thời gian cập nhật \\
\hline Tiêu chuẩn & GSMaP_MKV & & 3 ngày & 1 giờ \\
Gần thời gian thực & GSMaP_NRT & $0,1^{\circ} \times 0,1^{\circ}$ & 3-4 giờ & 0 giờ \\
Thời gian thực & GSMaP_NOW & & 0,5 giờ \\
\hline
\end{tabular}

Sản phẩm GSMAP_NRT (Near_Real_Time), sản phẩm mưa gần với thời gian thực với thuật toán vẫn dựa trên thuật toán chuẩn của GSMAP nhưng được giản hoá bớt ở một số quá trình nhằm giúp cho việc thực hiện được khả thi và thời gian trễ gần với thời gian thực. Và nguồn dữ liệu mưa GSMaP_NRT được đề xuất sử dụng trong nghiên cứu này. Một số ưu điểm của sản phẩm mưa vệ tinh được lựa chọn là dữ liệu GSMaP_NRT được JAXA cung cấp khá đầy đủ, ổn định trong nhiều năm, độ trễ về dữ liệu truyền

về là 3-4 giờ nên có thể đảm bảo được yêu cầu nghiên cứu và có khả năng tích hợp kịp thời để tính toán dòng chảy trong các hệ thống dự báo lũ.

Sản phẩm GSMaP_NOW với ưu điểm là sản phẩm được cập nhật thời gian thực, tuy nhiên sản phẩm này cần hệ thống máy tính cấu hình cao chuyên dụng để thu nhận từ vệ tinh khí tượng Himawari.

Sản phẩm GSMaP_MVK được JAXA lưu trữ với chuỗi số liệu lịch sử khá dài, đầy đủ, thuật toán xử lý hoàn chỉnh, được cập nhật các phiên 
bản phù hợp với nguồn thu từ các vệ tinh mới. Tuy nhiên, do độ trễ của GSMaP_MVK thường từ 3-4 ngày nên nguồn số liệu này được sử dụng trong các nghiên cứu đánh giá, phân tích, thường không sử dụng trong các hệ thống nghiệp vụ dự báo.

b) Số liệu thực đo

- Số liệu mưatừ 25 trạm đo trong và lân cận lưu vực có chuỗi số liệu lịch sử từ năm 2000 đến nay. Do điều kiện đo đạc tại các trạm, số liệu mưa thực đo thu thập được là lượng mưa 6 giờ. Bảng 2 tổng hợp các trạm đo mưa mặt đất có số liệu được sử dụng là đầu vào mô hình thủy văn.

- Số liệu mực nước và đường quan hệ $\mathrm{H}-\mathrm{Q}$ trung bình nhiều năm tổng hợp từ 2005 đến 2012 cho các vị trí thuộc khu vực trung lưu của lưu vực là Cẩm Thủy trên dòng chính sông Mã và Bái Thượng trên sông Chu, sông nhánh chính thuộc hệ thống sông Mã, được sử dụng xây dựng cơ sở dữ liệu đầu vào cho mô hình IFAS.

- Lựa chọn 4 đợt lũ để hiệu chỉnh từ năm 2000 đến 2008 (bảng 3) và kiểm định 2 trận lũ cuối năm 2008 và 2009. Các trận lũ được chọn xuất hiện tập trung trong 3 tháng lũ chính vụ từ tháng 8 đến tháng 10 nhằm đảm bảo sự tương đồng về thời gian và dòng chảy cơ bản trong sông.

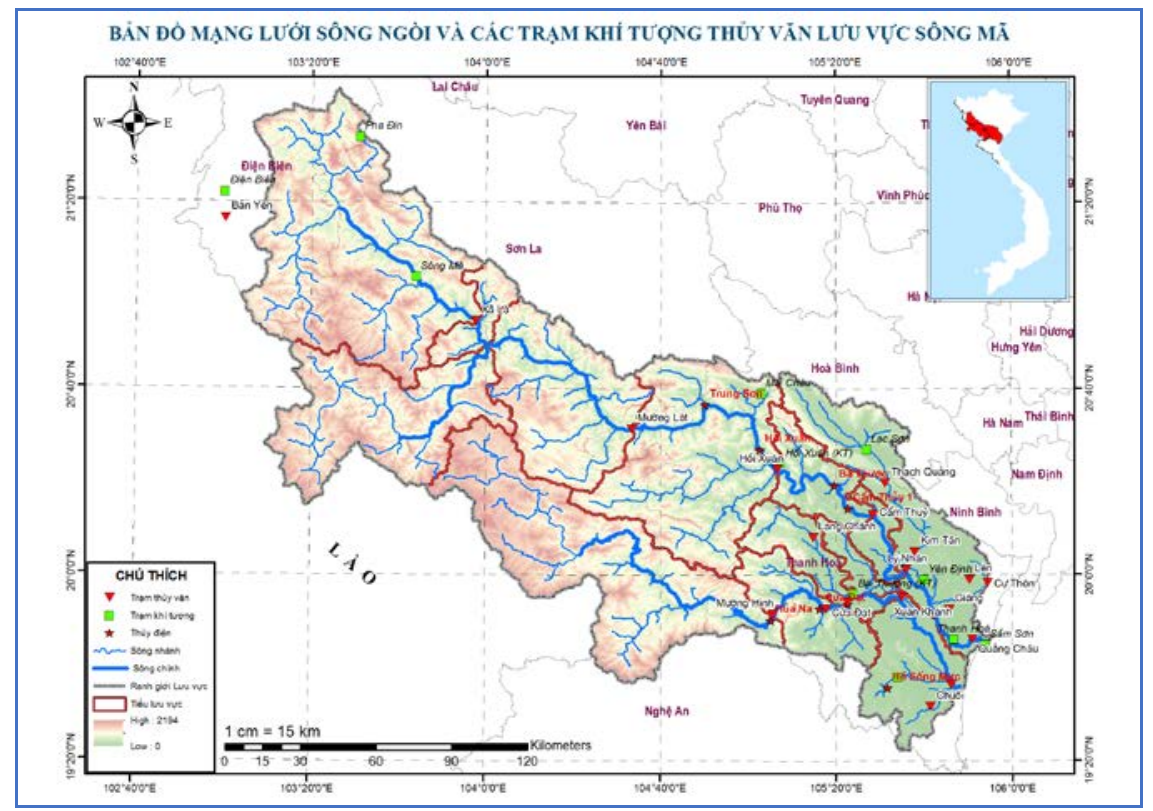

Hình 2. Mạng luoói trạm khí tượng thủy văn chính lưu vực sông Mã

Bảng 3. Đặc trung 4 trận lũ trên sông Mã tại Cẩm Thủy và sông Chu tại Bái Thượng

\begin{tabular}{cccccc}
\hline Trạm & Sông & Thời gian trận lũ & $\begin{array}{c}\text { Đỉnh lũ } \\
\left(\mathrm{m}^{3} / \mathrm{s}\right)\end{array}$ & Thời gian xuất hiện & $\begin{array}{c}\text { Biên độ lũ } \\
\left(\mathrm{m}^{3} / \mathrm{s}\right)\end{array}$ \\
\hline \multirow{3}{*}{ Cẩm Thủy } & \multirow{3}{*}{ Mã } & $27 / 8-22 / 9 / 2000$ & 4000 & $19 \mathrm{~h} 12 / 9 / 2000$ & 3346 \\
& & $14 / 9-15 / 10 / 2005$ & 4410 & $7 \mathrm{~h} 28 / 9 / 2005$ & 3756 \\
& & $25 / 9-21 / 10 / 2007$ & 7698 & $19 \mathrm{~h} 5 / 10 / 2007$ & 7358 \\
\multirow{3}{*}{ Bái Thượng } & $23 / 9-19 / 10 / 2008$ & 4100 & $23 \mathrm{~h} 27 / 9 / 2008$ & 2300 \\
& \multirow{2}{*}{ Chu } & $27 / 8-22 / 9 / 2000$ & 2390 & $19 \mathrm{~h} 11 / 9 / 2000$ & 2142 \\
& & $14 / 9-15 / 10 / 2005$ & 2480 & $19 \mathrm{~h} 14 / 9 / 2005$ & 2151 \\
& $25 / 9-21 / 10 / 2007$ & 3950 & $7 \mathrm{~h} \mathrm{5/10/2007}$ & 3784 \\
& $23 / 9-19 / 10 / 2008$ & 704 & $13 \mathrm{~h} 1 / 10 / 2008$ & 558 \\
\hline
\end{tabular}

c) So sánh hai nguồn số liệu mưa được tích hơp trong mô hìh

Hai nguồn số liệu mưa thực đo và vệ tinh có sự khác biệt lớn theo phân bố theo không gian, thời gian, giá trị lượng mưa. Hình 3 minh họa sự phân bố tổng lượng mưa và số ngày mưa cho 3 
trận mưa gây lũ lớn trong tháng 8 đến tháng 10 năm 2000, 2005 và 2007. Có thể thấy tổng lượng mưa GSMaP có xu thế thiên thấp so với lượng mưa thực đo tuy nhiên số ngày mưa GSMaP cao hơn hẳn so với số ngày mưa thực đo.
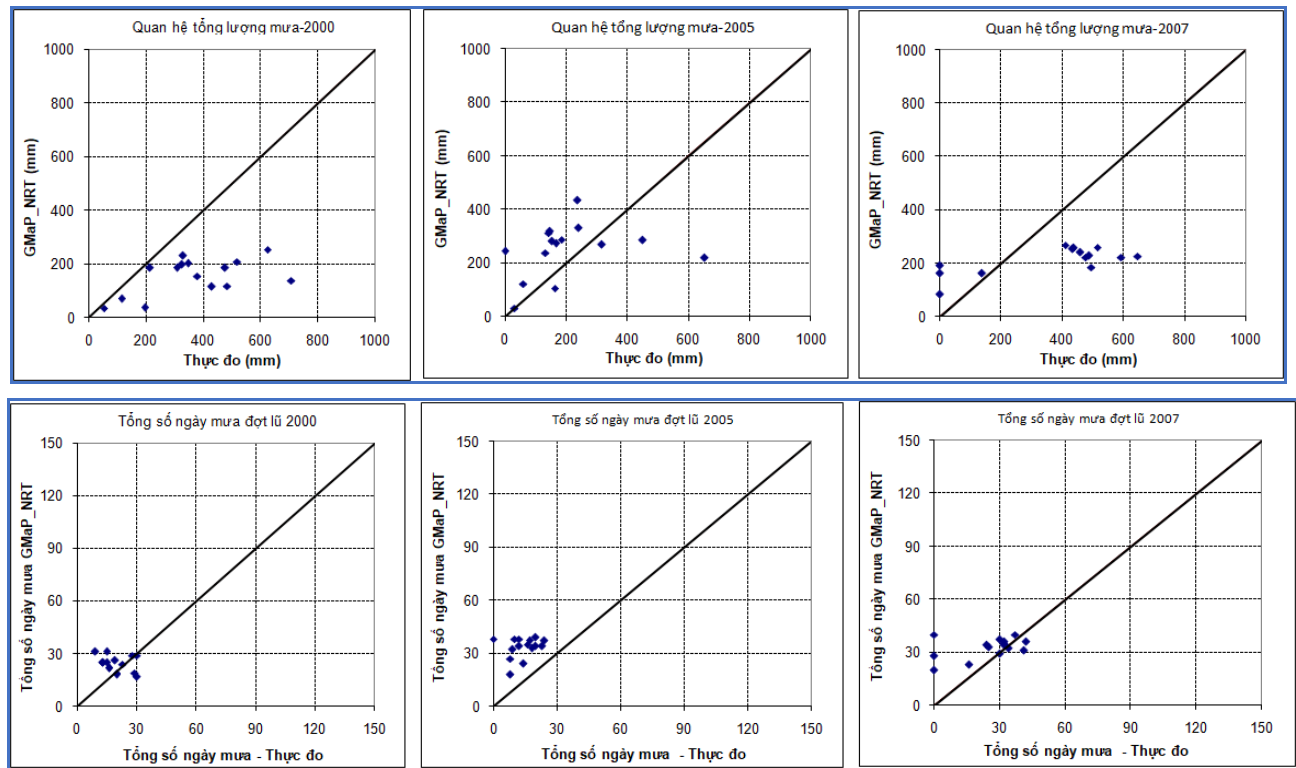

Hình 3. Phân bố quan hệ tổng lượng mưa và số ngày mua trong 3 trận lũ lớn năm 2000, 2005 và 2007

Sự khác biệt giữa hai nguồn số liệu mưa về phân bố theo không gian được minh họa ở hình 4 với việc mô phỏng sự phân bố của hai nguồn số liệu mưa được hiển thị khi tích hợp trong mô hình IFAS. Lựa chọn cùng một thời điểm xuất hiện lượng mưa lớn, có thể thấy sự khác biệt về vị trí xuất hiện tâm mưa và lượng mưa.

Qua sự phân bố mưa được minh họa ở hình 4, trên lưu vực sông Mã, mật độ trạm đo tập trung khu vực hạ lưu khá dày, do đó, hình ảnh tâm mưa thực đo xuất hiện rất rõ rệt. Đối với khu vực trung lưu và thượng lưu, mật độ trạm đo thưa thớt, đặc biệt khu vực thuộc Lào, phân bố mưa được xác định theo phương pháp nội suy (trong nghiên cứu này sử dụng phương pháp Kriging), do đó, mức độ tin cậy phân bố mưa cho các khu vực này còn hạn chế. Trong khi đó, phân bố mưa GSMaP xác định được các tâm mưa khu vực thượng lưu, đây là ưu điểm của nguồn mưa vệ tinh khi bao phủ được không gian lớn, nhất là khu vực không có trạm đo mặt đất.

Hai nguồn số liệu mưa thực đo và vệ tinh được tích hợp trong mô hình IFAS có sự khác biệt lớn theo phân bố theo không gian, thời gian,giá trị lượng mưa trong cùng thời điểm. Hình 4 minh họa trực quan sự khác biệt về vị trí xuất hiện tâm mưa và lượng mưa trong cùng một thời điểm giữa hai nguồn số liệu trong 3 đợt lũ năm 2000, 2007 và 2009. Có thể thấy lượng mưa GSMaP có xu hướng thiên thấp so với lượng mưa thực đo vùng hạ lưu lưu vực sông Mã, khu vực có mật độ trạm đo tương đối nhiều.

Đối với phân bố mưa thực đo trên lưu vực, tác giả sử dụng phương pháp Kriging, do vậy lượng mưa tại khu vực trung lưu sông Mã thuộc Lào là không có trạm đo sẽ có độ tin cậy không cao do thuật toán nội suy cho khu vực này kém. 

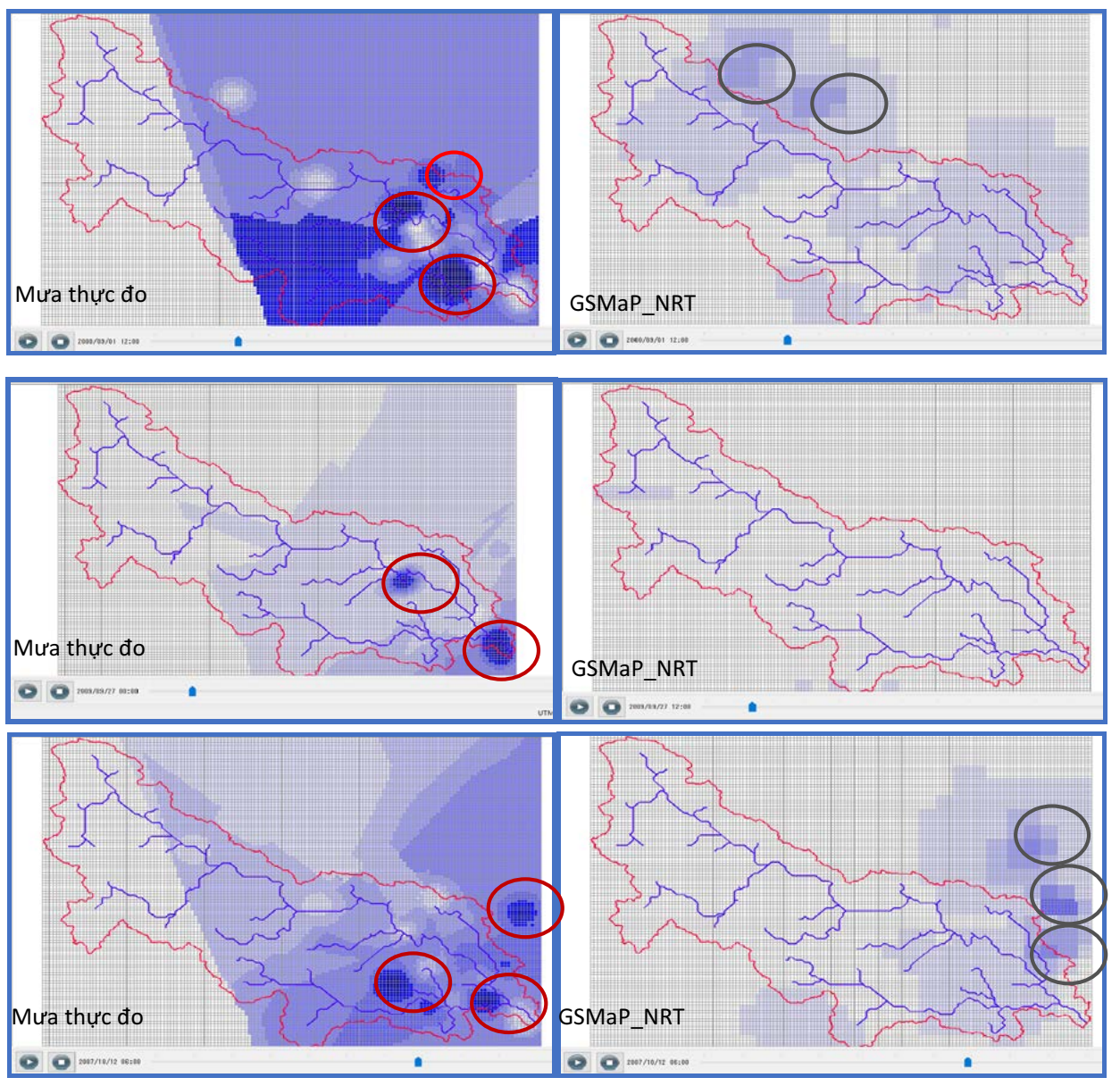

Hình 4. Sụ khác biệt về phân bố mura luu vực sông Mã với số liệu mura thực đo và mua GSMaP_NRT được tích hơp trong mô hìn IFAS

\subsection{Phương pháp đánh giá}

Trong nghiên cứu sử dụng tiêu chuẩn đánh giá chất lượng mô phỏng của mô hình là NASHSutcliffe:

$$
\mathrm{NASH}=1-\frac{\sum\left(\mathrm{Q}_{\mathrm{tt}}-\mathrm{Q}_{\mathrm{obs}}\right)^{2}}{\sum\left(\mathrm{Q}_{\mathrm{tt}}-\overline{\mathrm{Q}}_{\mathrm{obs}}\right)^{2}}
$$

Trong đó $\mathrm{Q}_{\mathrm{tt}}$ là lưu lượng lũ tính toán $\left(\mathrm{m}^{3} / \mathrm{s}\right)$;
Q obs là lưu lượng lũ thực đo $\left(\mathrm{m}^{3} / \mathrm{s}\right) ; \overline{\mathrm{Q}}_{\mathrm{obs}}$ là lưu lượng lũ thực đo trung bình $\left(\mathrm{m}^{3} / \mathrm{s}\right)$.

Hình 5 minh họa những số liệu cao độ số (DEM 30x30), bản đồ phân chia lưu vực sông Mã được tích hợp trong mô hình thủy văn IFAS. Phân bố mưa trên lưu vực với nguồn số liệu thực đo từ trạm mặt đất và dữ liệu mưa GSMaP_NRT tích hợp trong mô hình IFAS.

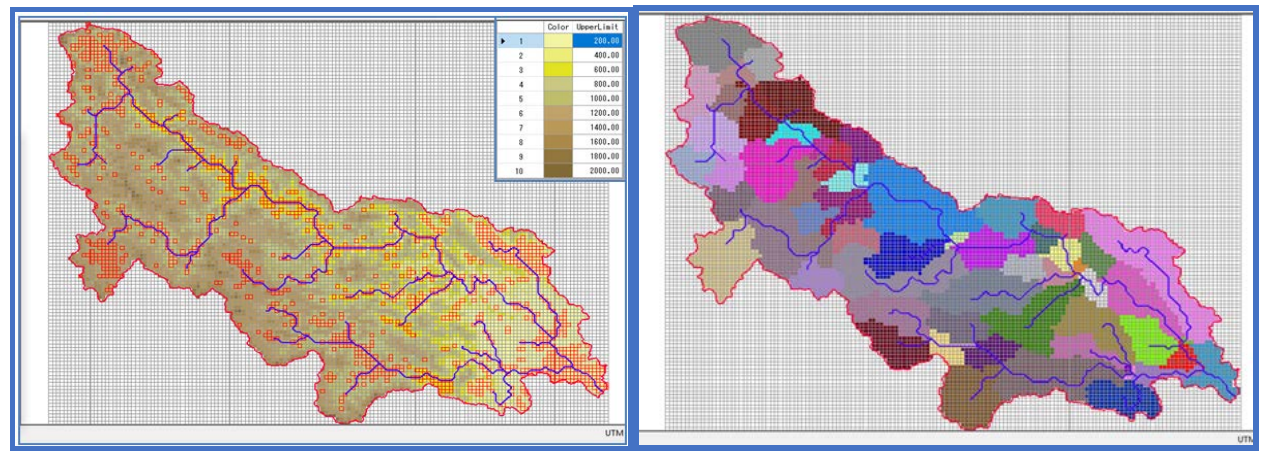

Bản đồ cao độ DEM

Bản đồ phân chia tiểu lưu vực trong mô hình

Hình 5. Bản đồ phân bố cao độ và phân chia lư vực trong mồ hình IFAS 
3. Kết quả nghiên cưu

Dựa trên số liệu mưa thực đo, hiệu chỉnh được tổng hợp ở bảng 4.

Bảng 4. Bộ thông số hiệu chỉnh cho mô hình IFAS

Tầng nước mặt

\begin{tabular}{|c|c|c|c|c|c|}
\hline STT & SKF & HFMXD & HFMND & HFOD & SNF \\
\hline 1 & 0.00055 & 0.1 & 0.01 & 0.005 & 0.7 \\
\hline 2 & 0.000025 & 0.05 & 0.01 & 0.005 & 2.0 \\
\hline 3 & 0.000015 & 0.05 & 0.01 & 0.005 & 2.0 \\
\hline 4 & 0.000002 & 0.001 & 0.0005 & 0.0001 & 0.1 \\
\hline 5 & 0.00002 & 0.05 & 0.01 & 0.005 & 2 \\
\hline \multicolumn{6}{|c|}{ Với thông số } \\
\hline \multicolumn{2}{|c|}{ Thông số } & \multicolumn{3}{|c|}{ Ý nghĩa } & Ký hiệu \\
\hline \multicolumn{2}{|c|}{ SKF } & \multicolumn{3}{|c|}{ Khả năng thấm } & $\mathrm{f}_{0}$ \\
\hline \multicolumn{2}{|c|}{ HFMXD } & \multicolumn{3}{|c|}{ Chiều cao trữ lớn nhất } & $\mathrm{S}_{12}$ \\
\hline \multirow{2}{*}{\multicolumn{2}{|c|}{ HFMND }} & \multicolumn{3}{|c|}{ Chiều cao dòng chảy sát mặt } & $\mathrm{S}_{11}$ \\
\hline \multirow{2}{*}{\multicolumn{2}{|c|}{$\begin{array}{c}\text { HFOD } \\
\text { SNF }\end{array}$}} & \multicolumn{3}{|c|}{ Chiều cao dòng chảy ngầm } & $\mathrm{S}_{10}$ \\
\hline & & Hệ s & im bề mặt & & $\mathrm{N}$ \\
\hline \multicolumn{2}{|c|}{ FALFX } & \multicolumn{2}{|c|}{ Hê số điều tiết $\mathrm{d} / \mathrm{c}$ sát măt } & & $\alpha_{n}$ \\
\hline \multicolumn{2}{|c|}{ HIFD } & \multicolumn{3}{|c|}{ Chiều cao nước ban đầu } & - \\
\hline \multicolumn{6}{|c|}{ Tầng nước ngầm } \\
\hline STT & AUD & AGD & HCGD & HIGD & \\
\hline 1 & 0.10 & 0.02 & 2.0 & 2.0 & \\
\hline 2 & 0.11 & 0.02 & 2.0 & .0 & \\
\hline 3 & 0.12 & 0.02 & 2.0 & .0 & \\
\hline 4 & 0.13 & 0.02 & 2.0 & .0 & \\
\hline \multicolumn{6}{|c|}{ Với thông số } \\
\hline \multicolumn{2}{|c|}{ Thông số } & \multicolumn{2}{|l|}{ Ký hiệu } & Ký hiệu & Đơn vị \\
\hline \multicolumn{2}{|c|}{ AUD } & \multicolumn{2}{|c|}{ Hệ số d/c sát mặt } & $\mathrm{A}_{\mathrm{u}}$ & $(1 / \mathrm{mm} / \text { ngày })^{1 / 2}$ \\
\hline \multicolumn{2}{|c|}{ AGD } & \multicolumn{2}{|c|}{ Hệ số d/c cơ sở } & & $1 /$ ngày \\
\hline \multicolumn{2}{|c|}{ HCGD } & Chiều cao d/c s & & & M \\
\hline & & Chiều cao ban & & & \\
\hline
\end{tabular}

Với bộ thông số được tối ưu, tính toán mô phỏng dòng chảy lũ với số liệu GSMaP. Đánh giá kết quả hiệu chỉnh mô hình IFAS với các trận

lũ từ năm 2000 -2008 dựa trên chỉ số mức độ phù hợp giữa tính toán và thực đo NASH được tổng hợp ở bảng 5 và các hình 6 - 9 .

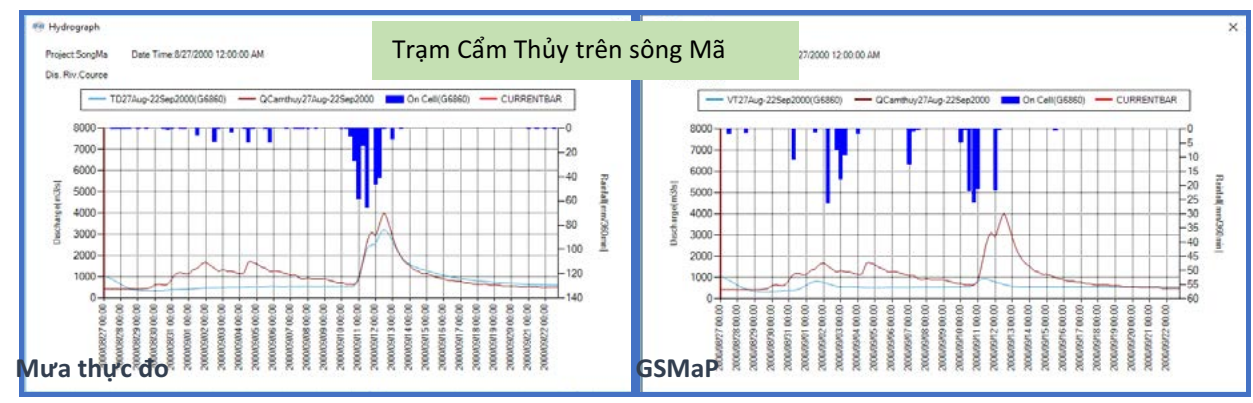




\section{BÀI BÁO KHOA HỌC}

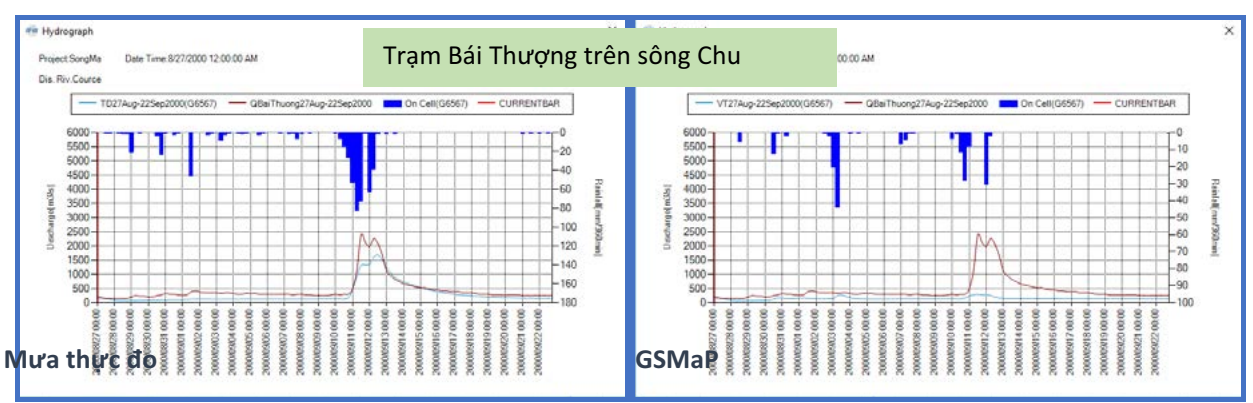

Hình 6. Kết quả mô phỏng dòng chảy lũ với số liệu thực đo và GSMaP_NRT tại Cẩm Thủy trên sông Mã, Bái Thuợng trên sông Chu (đợt lũ 27/8 - 22/9/2000)
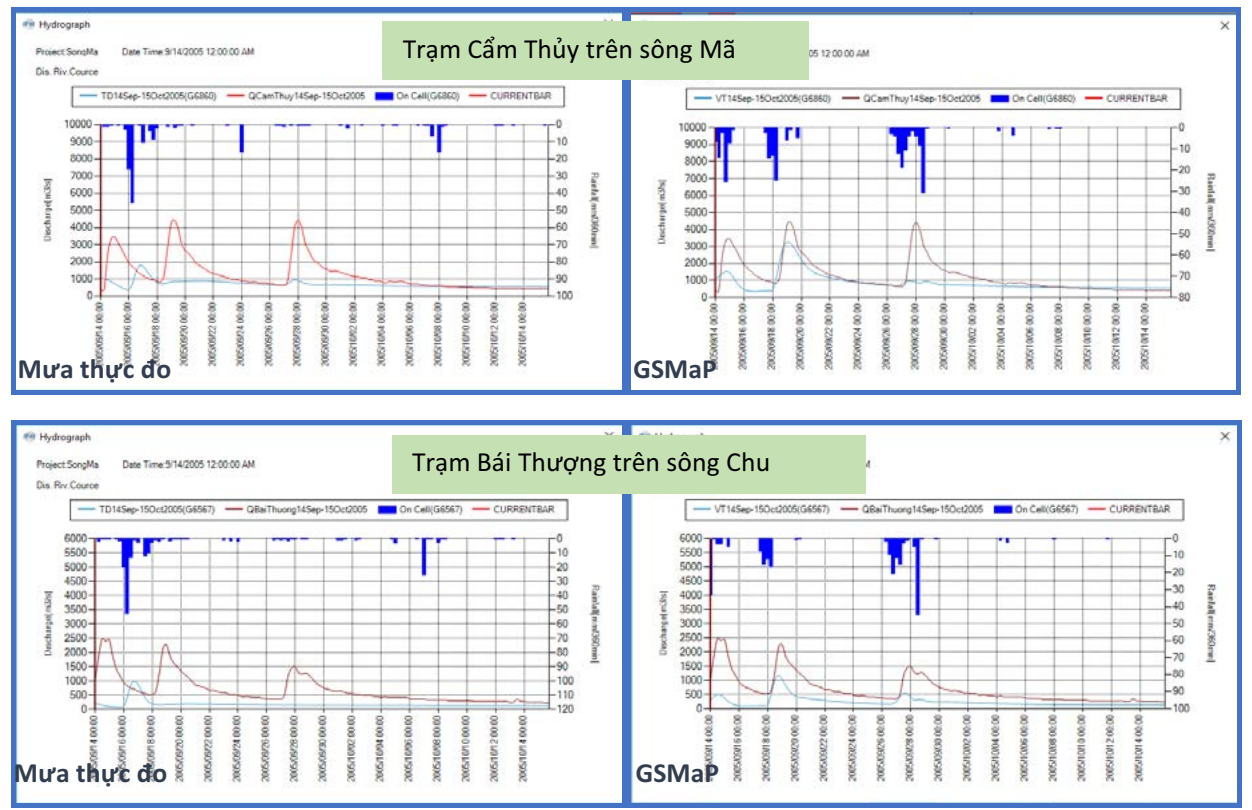

Hình 7. Kết quả mô phỏng dòng chảy lũ với số liệu thực đo và GSMaP_NRT tại Cẩm Thủy trên sông Mã, Bái Thượng trên sông Chu (đợt lũ 14/9 - 15/10/2005)
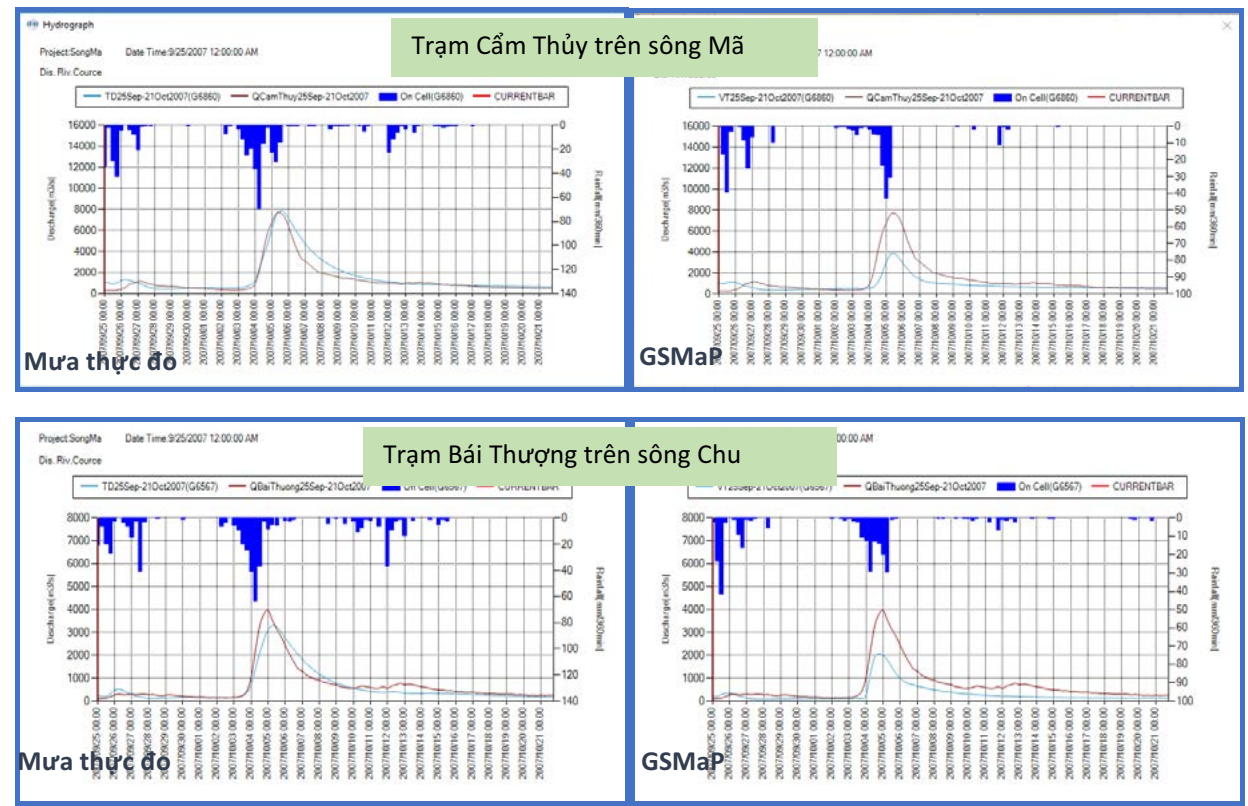

Hình 8. Kết quả mô phỏng dòng chảy lũ với số liệu thực đo và GSMaP_NRT tại Cẩm Thủy trên sông Mã, Bái Thuợng trên sông Chu (đọt lũ 25/9 - 21/10/2007) 

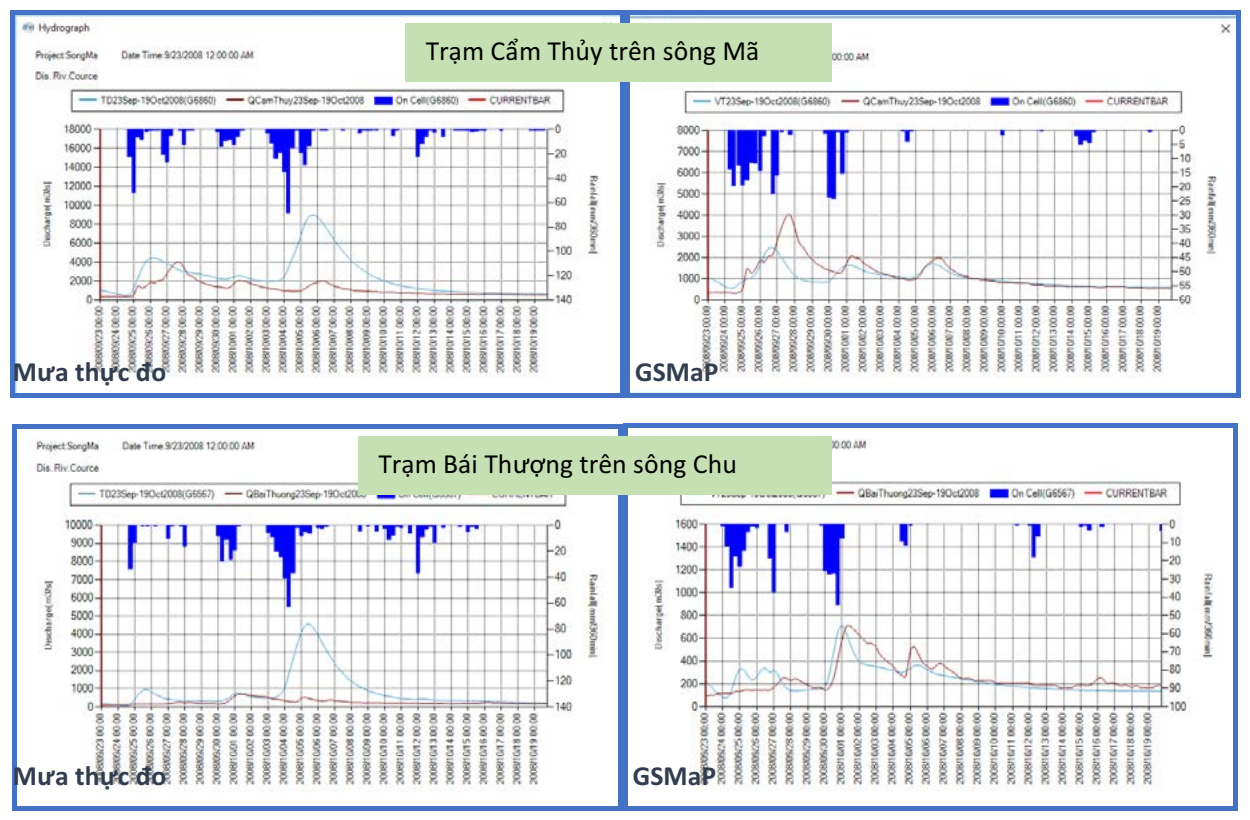

Hình 9. Kết quả mô phỏng dòng chảy lũ với số liệu thực đo và GSMaP_NRT tại Cẩm Thủy trên sông Mã, Bái Thương trên sông Chu (đợt lũ 23/9 - 19/10/2008)

Kết quả kiểm định 2 trận lũ lớn và vừa năm 2008 và 2009 được minh họa ở hình 10 và 11 .
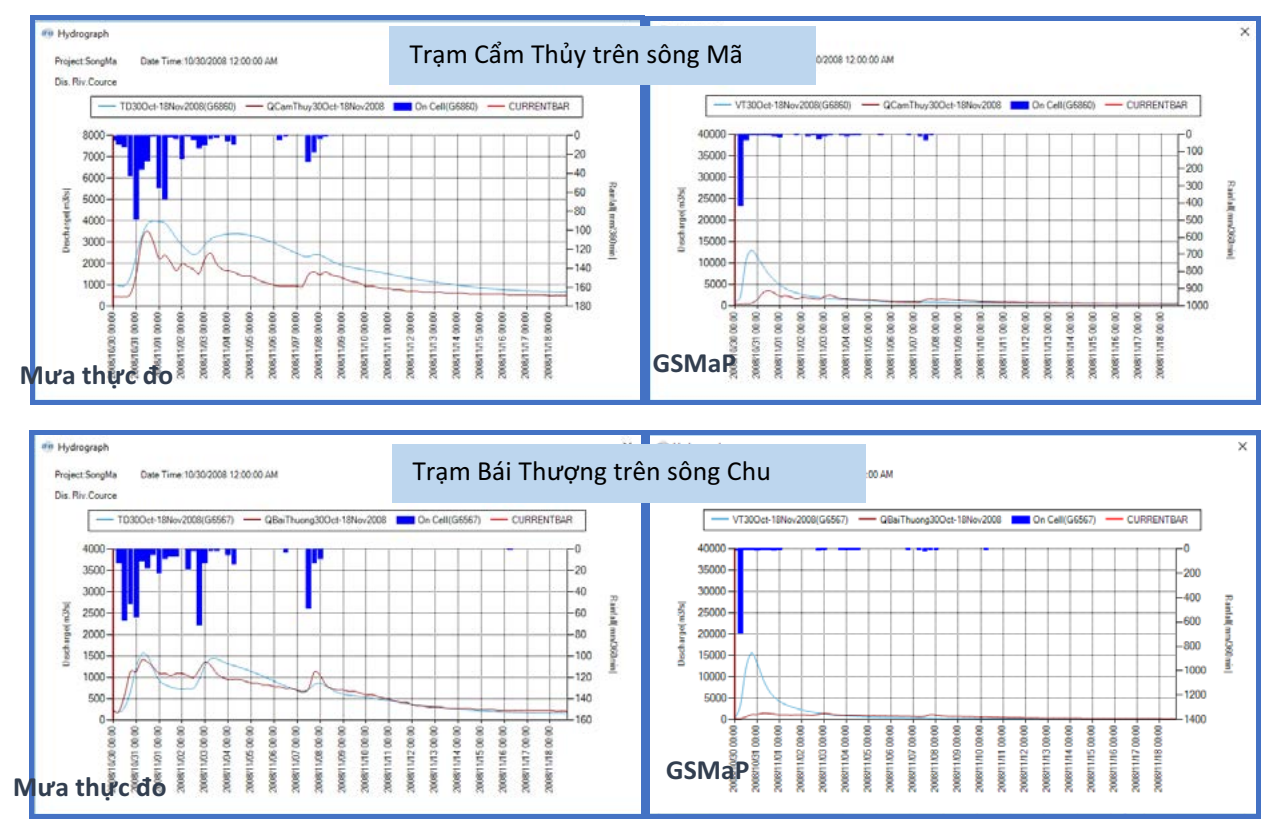

Hình 10. Kết quả mô phỏng dòng chảy lũ với số liệu thực đo và GSMaP_NRT tại Cẩm Thủy trên sông Mã, Bái Thuợng trên sông Chu (đọt lũ 30/10 - 18/11/2008) 


\section{BÀI BÁO KHOA HỌC}
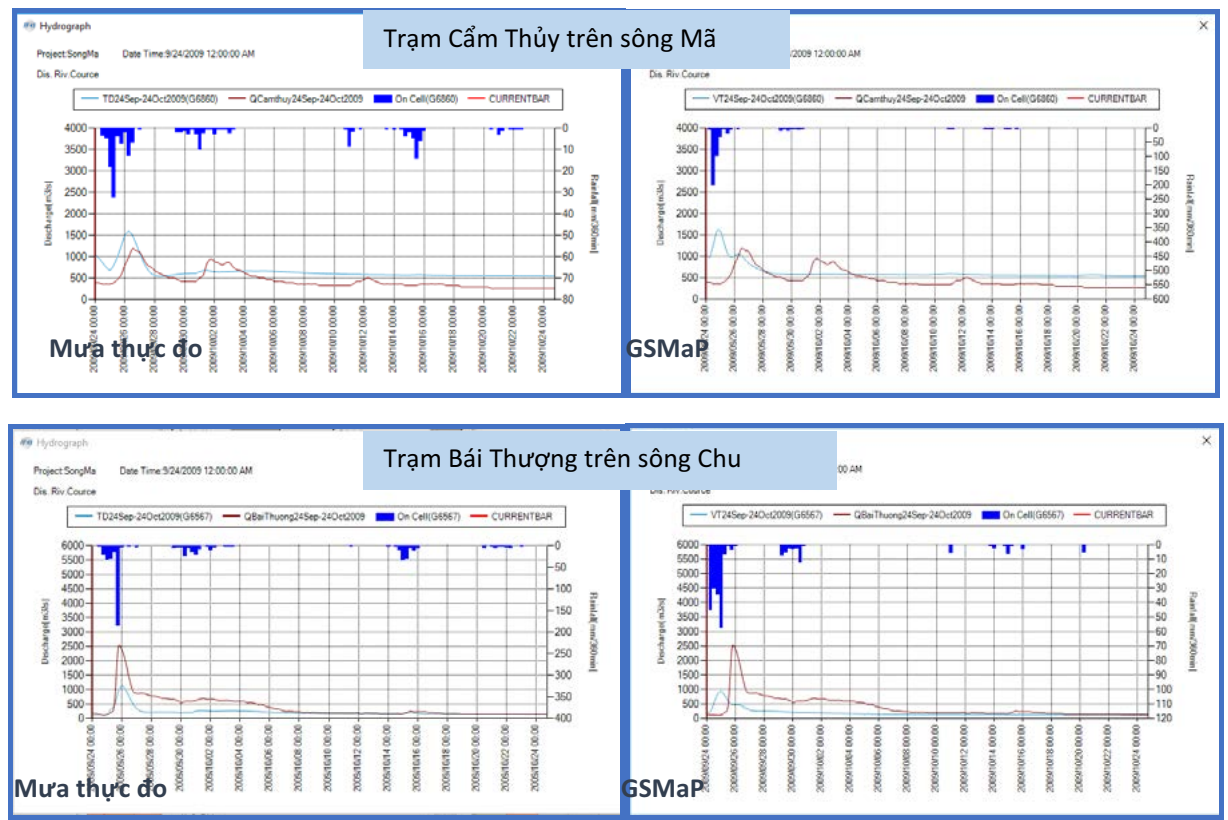

Hình 11. Kết quả mô phỏng dòng chảy lũ với số liệu thực đo và GSMaP_NRT tại Cẩm Thủy trên sông Mã, Bái Thượng trên sông Chu (đợt lũ 24/9 - 24/10/2009)

Bảng 5. Đánh giá kết quả mô phỏng dòng chảy lũ của mô hình IFAS dụa trên chỉ số NASH

\begin{tabular}{ccccc}
\hline \multirow{2}{*}{ Trạm } & \multirow{2}{*}{ Sông } & Thời gian trận lũ & Mưa thực đo & GSMaP_NRT \\
\cline { 3 - 5 } & & $27 / 8-22 / 9 / 2000$ & 0.48 & Ko mô phỏng được \\
Cẩm & \multirow{2}{*}{ Mã } & $14 / 9-15 / 10 / 2005$ & Ko mô phỏng được & 0.16 \\
Thủy & $25 / 9-21 / 10 / 2007$ & 0.91 & 0.52 \\
& & $23 / 9-19 / 10 / 2008$ & Ko mô phỏng được & 0.35 \\
Bái & & $27 / 8-22 / 9 / 2000$ & 0.75 & Ko mô phỏng được \\
Thượng & Chu & $14 / 9-15 / 10 / 2005$ & Ko mô phỏng được & Ko mô phỏng được \\
& & $25 / 9-21 / 10 / 2007$ & 0.94 & 0.49 \\
Cẩm & $23 / 9-19 / 10 / 2008$ & Ko mô phỏng được & 0.37 \\
Thủy & Mã & Kết quả đánh giá 2 trận lũ kiểm định & \\
Bái & & $24 / 10-18 / 11 / 2008$ & 0.42 & Ko mô phỏng được \\
Thượng & Chu & $30 / 10-18 / 11 / 2008$ & Ko mô phỏng được & Ko mô phỏng được \\
& & $24 / 9-24 / 10 / 2009$ & 0.83 & Ko mô phỏng được \\
\hline
\end{tabular}

Kết quả hiệu chỉnh mô hình IFAS cho các trận lũ lớn nhất năm 2000, 2005, 2008 và 2009 chưa tốt với hình thế thời tiết chính gây mưa - lũ là ảnh hưởng của bão, hoàn lưu bão đổ bộ khu vực miền Trung (bão số 4, WUKONG - 9/2000; bão số 6, VICENTE - 9/2005; hoàn lưu bão số 8 , KOPPU - 9/2009), phân bố mưa lớn trên lưu vực tập trung nhiều khu vực hạ lưu vùng Thanh Hóa - Nghệ An.

Năm 2007, đợt lũ lớn nhất trên lưu vực sông

Mã xuất hiện vào đầu tháng $X$ với nguyên nhân gây mưa - lũ lớn là do ảnh hưởng trực tiếp của bão số 5 (LEKIMA), phân bố mưa trải đều trên lưu vực từ thượng đến trung lưu sông Mã.Mô hình đã tính toán mô phỏng đợt lũ này khá tốt, chỉ số NASH là 0,91 tại Cẩm Thủy và 0,94 tại Bái Thượng.

Kết quả ở bảng 5 cho thấy, sử dụng mô hình IFAS mô phỏng lũ tại Cẩm Thủy trên dòng chính sông Mã có kết quả tốt hơn mô phỏng lũ cho vị 
trí Bái Thượng trên sông Chu. Mặc dù hai vị trí nằm ở khu vực trung lưu hệ thống sông Mã, tuynhiên, khu vực trung lưu vực sông Chu có một phần thuộc Lào, là nơi không có thông tin và số liệu mưa nên phần nào ảnh hưởng đến phân bố mưa thực đo theo phương pháp Kriging, do đó ảnh hưởng đến tính toán dòng chảy lũ từ mưa khu vực trung lưu sông Chu.

Sử dụng số liệu mưa vệ tinh GSMaP_NRT là đầu vào mô hình IFAS, kết quả tính toán cho thấy việc sử dụng nguồn số liệu này chưa mô phỏng được dòng chảy lũ trên dòng chính sông Mã và sông Chu. Đặc biệt, trận lũ các năm 2000, 2008 và 2009 cho thấy phân bố mưa vệ tinh tại Cẩm Thủy và Bái Thượng không tương thích với lượng dòng chảy lũ thực đo, phần lớn là thiên thấp so với thực tế.

Tuy nhiên, một số trường hợp như trận lũ vào tháng 9 đến tháng 10 năm 2005 và 2008 cho thấy, sử dụng mưa vệ tinh cho kết quả tính toán dòng chảy khả quan hơn khi sử dụng số liệu mưa thực đo, đặc biệt trong một số trường hợp, dòng chảy tính toán với lượng mưa vệ tinh tuy thiên thấp về giá trị nhưng khả năng bắt đỉnh lũ tốt hơn dòng chảy tính toán với mưa thực đo như trận lũ năm 2005 và lũ lớn năm 2007.

\section{Kết luận}

Nghiên cứu này đã ứng dụng mô hình thủy văn IFAS tính toán mô phỏng dòng chảy lũ khu vực trung lưu lưu vực sông Mã. Đây là khu vực có mạng lưới trạm khí tượng thủy văn hạn chế, do đó, tác giả sử dụng hai nguồn số liệu mưa thực đo từ các trạm mặt đất và mưa vệ tinh GSMaP nhằm mục đích đánh giá chất lượng mưa vệ tinh qua kết quả mô phỏng dòng chảy lũ trên lưu vực sông thiếu số liệu trong khoảng thời gian lưu vực sông ít chịu tác động của các hệ thống hồ chứa.

Dựa trên chỉ số đánh giá mức độ tương thích giữa kết quả tính toán và thực tế NASH-Sutcliffe, kết quả mô phỏng dòng chảy không được tốt khi sử cả hai nguồn số liệu mưa.

Nhiều nghiên cứu học đã kết luận "số liệu ước lượng mưa viễn thám không thể sử dụng thay thế với mô hình thủy văn được hiệu chỉnh với số liệu mưa thực đo tại các trạm mặt đất, trừ khi được hiệu chỉnh lại với số liệu mưa vệ tinh" $[1,6]$. Tuy vậy, qua nghiên cứu này, một số trường hợp cho thấy sử dụng mưa vệ tinh mô phỏng lũ cho kết quả tốt hơn khi sử dụng số liệu mưa thực đo, từ đó, tại những khu vực với thực trạng quá ít hoặc không có dữ liệu mưa thực đo, việc sử mưa vệ tinh là đầu vào mô hình thủy văn là giải pháp có thể chấp nhận được "something better than nothing".

Trong một số trường hợp, sử dụng mưa vệ tinh cho kết quả tính toán thời gian xuất hiện đỉnh lũ tương đối sát với thời gian đỉnh lũ thực tế, trong khi đó, dùng mưa thực đo mô phỏng độ lớn trận lũ tốt hơn, từ đó, định hướng nghiên cứu về việc hiệu chỉnh độ sai lệch giữa guồn số liệu mưa vệ tinh và thực đo là cần thiết, nhằm sư dụng hiệu quả hơn số liệu mưa vệ tinh trong tính toán lũ.

\section{Tài liệu tham khảo}

1. Artan, G., et al. (2007), Adequacy of satellite derived rainfall data for stream. Natural Hazard, 167-185.

2. Hossain, F., Katiyar, N., Hong, Y., Wolf, A., (2007), The emerging role of satellite rainfall data in improving the hydro-political situation of flood monitoring in the under-developed regions of the world,. Nat Hazards, vol. 43 , 199 - 210.

3. Hafiz, I., Sidek, L.M., Basri, H., Hanapi, M.N., (2013), Application of Integrated Flood Analysis System (IFAS) for Dungun River Basin. Conference Paper in IOP Conference Series Earth and Environmental Science. Doi: 10.1088/1755-1315/16/1/012128.

4. Phòng khí tượng thủy văn, Viện Quy hoạch Thủy Lợi (2014), Báo cáo thủy văn Hà Nội: Dự án rà soát quy hoạch thủy lợi lưu vục sông Mã. 


\title{
BÀI BÁO KHOA HỌC
}

5. Shrestha, Singh, M., (2011), Bias-Adjustment of Satellite-Based Rainfall Estimates over the Central Himalayas of Nepal for Flood Prediction, Kyoto, Thesis or Dissertation.

6. Đặng Ngọc Tĩnh (2013), Nghiên cưu ưng dụng số liệu vệ tinh mưa dụ báo số trị kết hợp số liệu bề mặt trong dự báo lũ hệ thống sông Hồng - Thái Bình. Hà Nội: Báo cáo tổng kết đề tài nghiên cứu khoa học cấp Bộ.

7. Tsukuba (2009), Integrated Flood Analysis System (IFAS version 1.2) User's Manual. Japan: Public Works Research Institute (PWRI). International Centre for Water Hazard and Risk Management under the auspices of UNESCO (ICHARM).

\section{APPLICATION OF IFAS HYDROLOGICAL MODEL FOR SIMU- LATING THE MIDDLE REACH OF THE MA RIVER BASIN Nguyen Tien Kien ${ }^{1}$ \\ ${ }^{1}$ National Center for Hydro-Meteorological Forecasting}

\begin{abstract}
Currently, many kinds of rainfall data sources as radar and satellite products have been integarated in flood forecasting systems in the world for supplementing and combining with the observation in the system, especially flood forecast system in hydro-meteorological agencies from USA, Japan, China, Korea ...This study presents the simulation results of flood flows on the Ma River main stream based on the application of IFAS hydrological model from Japan Institute of Public Work (PWRI)s. The model input data sources include observed rainfall and GSMaP_NRT satellite rainfall product. The flood flow simulation results show that the situation of sparse station network is a important cause leading tobad results of flood flow simulation for upper and middle reaches of the Ma river with both observed rainfall and satellite rainfall input data. Based on model results, some cases of using satellite rainfall show better results in comparing with using the observed rainfall, it is the premise to consider the application of the satellite rainfall data as input hydrological model to calculalate flood flow for areas without or few measurement stations such as the middle and upper parts of Ma river basin.
\end{abstract}

Keywords: GSMaP_NRT, Ma River basin, Flood flow simulation, IFAS model. 